\title{
Leadership and Competence Development in Higher Education: Reconstituting the Human - Machine Interfaces in the Space of Digital Systems
}

\author{
Milan Jaros* \\ Philosophical Studies, Newcastle University, Newcastle upon Tyne, NE1 7RU, United Kingdom \\ *Corresponding author: Milan.Jaros@ncl.ac.uk \\ Received August 08, 2014; Revised September 19, 2014; Accepted October 08, 2014
}

\begin{abstract}
It is an outstanding intellectual and leadership challenge in higher education to develop effective 'competence' delivery and evaluation practices complementary to and building upon the traditional programs. The key obstacle is the growing generic gap between systems of thought and organization governing the established curriculum and those required for decision making conditioned by the radical changes in the divisions of labor. It is argued that this decision making takes place in an open problem space in which success depends on being able to recognize and make use of the pathways imposed upon us by digitalization of knowledge systems and work practices. These are the highways along which the current thoughts and material exchanges travel and collide, and which condition the much needed synergy of inputs spanning disparate knowledge and power systems. Two aspects of this structural problem are of particular interest here. Firstly, the boundary separating human and machinic contributions have become blurred beyond repair. Secondly, the failure to recognise fully the impact of new work practices amounts to de facto abdication by humans from taming runaway complexification. This rapidly reduces the space in which to make efforts required to ensure that the human condition - and the standing of higher education as a guardian of the consititutive role of human -human engagenment in particular - remain open for debate and perpetual re-positioning in rapidly changing circumstances. The aim here is to establish pedagogy for a fresh reappraisal of this constitutive process in the liminal space of human and machinic contributions, and one capable of engendering the human-centered character of University without depriving staff and students of benefits brought by the maturing post-mechanical culture.
\end{abstract}

Keywords: leadership and methodology in higher education, competence development and evaluation, humancentred pedagogy in the space of digital systems, interdisciplinarity

Cite This Article: Milan Jaros, "Leadership and Competence Development in Higher Education: Reconstituting the Human - Machine Interfaces in the Space of Digital Systems." American Journal of Educational Research, vol. 2, no. 10 (2014): 898-905. doi: 10.12691/education-2-10-8.

\section{An 'Executive' Overview}

As the Western educational systems enter the maturing digital age, their inertial structures are being challenged by the rapidly growing gap between the practices dictated by novel divisions of labor and the systems of thought and organization dominating the traditional curriculum delivery. These novel practices are characterized by spectacular gains achieved via rapid complexification and networked subdivisions of production. This is chiefly because of the fundamental shift in operational meanings of knowledge and the human subject. One of the key consequences of this state of affairs is the growing delay in matching graduates with the functioning of productive structures - while the digital systems are allowed to acquire a life of their own.

Two aspects of this structural problem that present fundamental obstacles to a change of methodology in curriculum delivery are of particular interest here. Firstly, the human and machinic contributions have become - at least for practical purposes - only partially separable. This is in contrast with the outlook which has been a grounding influence on human thought and organization since the days of Rene Descartes and John Locke and which still informs - be it under various disguises - most of the curriculum delivery. Secondly, the failure to take on board the full impact of complexification on work practices amounts to de facto abdication by humans from any responsibility for shaping and taming products of their labor. This rapidly reduces the space in which to make efforts required to ensure that the human condition - and its standing in higher education in particular - remain open for debate and perpetual re-positioning in rapidly changing circumstances.

It has been argued that these challenges be approached as a methodological task that is best addressed in a bottom up, context-driven, iterative method designed to offer students an opportunity to actualise better their specialist skills by learning to formulate problems in conditions 
which require them to interrogate and synergise disparate knowledge systems. Such structures are peculiar to the functioning of material production and human organisations of the maturing digital age. In this approach, the curriculum is structured as a project-based, contextconditioned, iterative learning process. The emphasis is on personal choice and responsibility for what is being done and for what purpose. It is to identify and nurture a personal portfolio of skills leading the student into a worthy employment niche. This is a way to bring about a shift from the prevailing top-down instruction and management strategies fenced off by subject boundaries to a bottom up, student-tutor centered, iterative learning process grounded in but reaching beyond the conventional academic subject. The 'outcome' and its 'value' are determined through the process of iterative interrogations of knowledge systems and digital structures, individuals and institutions fully acknowledged as relevant to the task in hand but never fully controlled by the interrogator. Both the learner and the tutor are 'nudged away' from their specialist starting point by close encounters with the concrete (empirical) demands of the real world place and event coordinates. They seek iteratively competent choices leading to the desired 'product' which 'converged' to an outcome marked by the limits imposed by the continuous re-assessment of the assignment in the light of the work conditions. The methodological guidelines for implementing this procedure in a standard university environment and some of the results achieved have been presented elsewhere [1].

Recent attempts at top-down reforms of higher education whether driven by left or right doctrinaire wills have been made largely ineffective by unintended outcomes. That is indeed what is expected if one recognizes to what extent the higher education domain resembles even on the modest of terms a complex social system [2,3]. The long overdue shift in Higher Education to smaller, semiindependent units, free to make rapid re-alignments and re-connections to human and non-human resources in order develop and implement effectively their missions, has in fact been much advanced in business and production structures! In University, any structural change - and competence development in particular - is likely to be best achieved gradually, by ways complementary to and building upon the traditional degree delivery. The initial moves might be incremental, step like, person to person interventions, "nudgingly" persuading [4] individuals and interested groupings of the advantages the supplementary structures and their influence on reforming higher education at large bring to employment prospects and personal satisfaction. And, more significantly, to protecting and advancing the human-centered character of University, without depriving students and staff of active participation in the new technologies and social structures on which our prosperity depends!

\section{From Yesterday to Today: What is there to Sustain?}

On the 14th of October 1806, Napoleon's army utterly defeated the Prussians at Jena. Within a few weeks the whole of the Prussian war machine, the jewel in the Prussian Crown, was destroyed. For Professor Georg
Friedrich Hegel this meant that the achievements of the French Revolution were here to stay; it was the End of History, and he was the first to "know" it, he was the Last Man. As for the Prussian elite, they realized that this humiliation was not due to lack of resources, courage or bad luck; the French gunners seemed to be moving in a different space! No lesser mortal than Wilhelm von Humboldt was called upon to lead the spiritual renewal. Fichte and Schleiermacher were commissioned to submit proposals for a new University. Humboldt's report, in which he justified his decision to the Minister of State, has served in the course of the $19^{\text {th }}$ century as a blueprint for University charters all over the Western world.

Humboldt went against Fichte and in favor of Schleiermacher's proposal. He wanted an institution that would pursue knowledge for its own sake. This institution of the modern future lives and renews itself according to its own inner principles and without reference to any external goal or control. The human project of Enlightenment was a project of liberation of humans from being subjected to an arbitrary power of another human being, from ignorance and caprices of nature. The philosophy of empirically grounded rationality born out of Galileo's intervention under the motto "the book of nature is written in the language of mathematics" replaced Revelation with 'measure and quantify', with Kant's autonomous mind a la Newton. Galileo separated humans from things and reduced nature to an object to be mastered. Gone was Aristotle's Cosmos as a purposeful, stable unity of things, humans and gods in which 'knowledge' was obtained via revelation in a moment of holy madness. In modern epistemology of Kant's Critiques, knowledge is only knowledge when it is universal and disinterested, grounded in the logical categories of pure reason applied to that which is thinkable and presentable. Only then does it legitimate itself as distinct from mere opinion and petty squabbles. Needles to add, it is was this autonomous mind that gave us not only the law of gravitation and the calculus, clean water and penicillin, but also the declaration of human rights and a vote! For Kant the right to be moral was to be autonomous; this autonomy was not a gift from kings or socialists but a transcendental right.

If there is anything to be 'sustained', it is surely this notion of individual and collective freedom as Independence and Right. Our problem with this legacy today is that what we have come to regard, at least in principle, as the necessary condition for civilised life, can no longer be unconditionally legitimated in the way posited by the Founding Fathers. The space and time in which much of living and knowing is now acted out, 'actualised', are no longer reducible to Newtonian 'absolutes', the 'forms of perception' taken as a legitimate approximation by Kant - and, until very recently, be it in a variety of disguises, by most Western thinkers and doers! And for the best of reasons: it is this approximation that informed and assured in the course of the last five hundred years or so the brilliant choice of just that level of complexity at which there are soluble problems in physical and social sciences, and one on which even the 'digital machines' and 'rocket science' depend. However, it also a fact that in the course of the last two hundred years our 'experience of time and matter' has been branched and its energy channelled into many different 'levels of existence', e.g. 'molecular', 'viroid', 'genomic', 
'galactic', 'networked' etc. [5] each with its own different - and often incommensurate with others - level of complexity, ever changing scales and units of performance, with its own 'metric'! In the eighteenth century, it was very reasonable to assume that Nature is a neutral referent. In the absence of microscopic and quantitative tools, in fact available to us only gradually in the course of the last hundred years, there was no empirical evidence to contradict that approximation as the model of the world. Since that time, humans have acquired the power to master natural forces and impose a multitude of body and mind-invasive structures upon them. Meanwhile, the density of human population and particularly of the interconnections among them has grown exponentially, with the social structures for enabling fair and smooth functioning of the industrial and governance power structures increasingly lagging behind. It is no longer just that we measure, quantify, and connect but how! Even if we were to accept without reservation the words of the Founding Fathers of modernity about rights and independence, we would still be compelled to re-negotiate the meaning of those ideas as we project them again and again upon the new layers of the broken Cosmos, on the fragmented reality of the runaway flow of objectified material exchanges and networked structures on which we nevertheless depend for survival! Without effective projections of the scientific and logical-linguistic (social) accounts of movements of life upon the 'local' realities at the site of inquiry and experimentation, the inquiring mind would not be able to recognise the traces of invisible inscriptions left behind by 'models of the world in action'. If the 'truth', the power of these inscriptions that rules the world cannot be acted upon, it remains merely formal, unmatched to where and at what communicable level it is human - experienced, where it comes into being, where its energy rises and decays.

\section{The Great Reversal}

In his much quoted Report on Knowledge (prepared in the late 1970s), J-F. Lyotard [6] takes up the story of Humboldt's report and goes on to contrast it with the coming reversal. Although Lyotard's book was savaged at the time as unjustifiably alarmist, to a practicing academic of today his picture of the reversal of Humboldt's ideas and of the forthcoming shift in the human condition must appear quite modest. Certainly when judged on the scale of the current state of affairs!

There has been since the 1980s much lament from all quarters - and in educational contexts in particular - about the shift from institutional and individual autonomy, from guarantees of independent disinterested inquiry, and to mindless league tables driven by money making, by 'inflation' of boutique topics in syllabus, and by administrative measures to please the student-customer and the Paymaster Establishment alike. No wonder that many share concerns like those expressed by Professor Standish [7] who spoke against "tranquilized acquiescence in surveillance and accountability" and "technicist managerialism with its presumption of transparency and control". In the same volume Skillen opened his article with "The politics and pedagogy of schooling are becoming more authoritarian, coercive and utilitarian.
Reactionary ideologies dressed and patched up with new managerialism already moribund in the market place..."(ibid. p.375).

Such laments have been overtaken by events; the direction of change so ably announced by Lyotard's study has now been well established, and his predictions of a reversal in fact greatly exceeded by the waves of privatisation, by wholesale commodification of scientific and social research and their role in constituting the Common which is now chiefly a rich source of rent [8]. The Crash of 2008, far from taming the runaway complexification and bringing about a correction, has in fact greatly strengthened the very forces that had led to it [9]. Since many in the post 1980 generation owe their career advancement to promoting the status quo established in the course of the last three decades, there is little chance of bridging the gaps discussed in the above paragraphs by a radical top-down reform.

\section{Developing Competence: What is being done?}

In February 2011, a consortium of educationalists from leading German universities organised in central Berlin a symposium on modelling and measurement of competences in higher education [10]. Its purpose was to launch a new research project, well supported by the Federal government of Germany and by a number of industrial and business organisations. It was to initiate and provide guidelines for what can be described as a structural shift in the attitude to the notion of professional competence expected from graduates in the maturing 'digital age'. A number of distinguished speakers, from the United States, Australia, and Germany - to name just the best represented countries were invited to review the state of the art in this field. The first striking feature of those presentations was that most of those who had 'punchy things to say' about work on competence development were not currently practicing in a recognisable university department (e.g. of physics, history, etc.) or in a leadership position. However, most had served in such positions previously, often at a very senior level. They were currently heading a private or public organisation or team - funded, for example, by American Federal Sponsors, by large American industrial and business corporations, and also by some international educational organisations. The main thrust of their programmes was in essence to develop computer software for delivery and examination of selected specialist themes, with a view to prepare the candidate - who would have typically reached the last stage of a specialist degree programme - for facing the task of making decisions in an open problem space such as that one encounters in the 'real life' situation (e.g. to build a road, an airport, to set up a trading node, etc.). Naturally, in a way such sponsors thought best; the key incentive for governmental and corporate intervention was their sense of urgency in ensuring that graduates are better prepared for the new conditions in which they have to function. Although there was little or no attempt to go much beyond a somewhat broader notion of any given speciality, there was a conscious effort to prepare and to test the candidates in problem formulation; that is what invariably happens when 'the solution' they were trained to master is only one of the necessary but not a sufficient condition for making progress. 
In spite of this, the speakers lamented, when they offered their wares to existing specialist programmes, they were almost always turned down by the professoriate.

In his keynote address at this meeting, Professor Richard Shavelson presented an accomplished state of the art study of competence modeling and measurement. He started from the premise, shared by other authors, that "...competence is a...complex ability...that... (is) closely related to performance in real-life situations" [11]. When the gloves are off [1], it is simply that which enables the learner to interrogate and synergize [12] disparate knowledge systems we never fully understand and control but on whose success we depend [13,14,15]. Whereas benchmarking of specialist skills has been much studied, even the concept of competence - and particularly the methodology capable of gradually integrating it with and bringing about the relevant changes in the existing educational structures - presents a "methodological challenge" in what is a "widely neglected research field" [16]. The problem itself is not unknown or lacking in official recognition even among the high echelons of the Establishment. The former vice-chancellor of Leeds University, knighted for his services to the British Establishment, cried that a "sea change is needed" [17]. Alas! "Is the higher education bubble about to pop?" "...the dark hordes of forgotten students who leave the university as Napoleon's army left Russia, uninspired by their courses, wounded in many cases by what they experience as their own failures, weighed down by their debts..." - thus spoke the distinguished reviewer of six monographs on American Higher Education [18]. In another review, Professor Alan Ryan took the reader through a book by Howard Gardner [19] - a rare philosophy and history rich analysis of the present status quo including the fallible Wikipedia, instant gratification syndromes, but also expressions of his faith in the survival of 'elementary goodness' in young people! The most recent testimony, a film called Ivory Tower, is even more outspoken - as is the review welcoming the work under the title "The Hi-Tech Mess of Higher Education" [20].

What is of interest here is that the reviewers and indeed their authors rarely moved beyond critique of critique, warnings and concerns - chiefly about how to protect the youths from the products of the digital age! No sign of reforms creating space for a genuinely contemporary social contract - and one in which robots and other machinic systems are no longer treated as if they were another more or less desirable version of telephone landlines! The authors chosen for the above sample of opinion seem to be no exception! It is astonishing that the common factor, indeed the most noticeable concern of all fifty thinkers selected to represent educational thought in the $20^{\text {th }}$ century by Professor Palmer, a senior educationalist and academic [21] - in spite of covering just about all possible permutations of the few variables offered by this discourse - is again their determination to protect the new generation from anything that the new divisions of labor, and the digital technologies and structures driving them in particular, may impose upon them. There are no or very weak proposals for a structural change that would spell out and promote practices enabling the society to develop a new, stable and sustainable concord between the machinic systems humans create and the human purposes to which they should serve.
Undergraduate syllabuses as well as governmental pronouncements always imply the existence of some law like solutions and truths, to justify, say, money printing or forbidding air hostesses to wear a cross! This is in spite of glaring demonstrations of the irrelevance of top-down control such as the Crash of 2008 (see, for example, the analysis offered in refs. 9, 14, 15) - not to speak of the familiar failures of the n-th educational or health service reform - in Britain and elsewhere! The 'soluble' tasks on the syllabus of today can be more profitably learned and exercised with the help of interactive software by now well prepared by professionals from leading Institutions. The above mentioned iterative, bottom up procedure enabling recognition and parameterisation of the task taken out of the laboratory or lecture room, the problem contextualisation and re-formulation, always requires a new kind of understanding and clarification. It is not only to facilitate better technical choices; after delegating technicalities to computer resources, the 'instruction' becomes almost entirely grounded in collegial interchanges, to a fresh source of active nourishment of critical and consensual human practices via person to person contacts. Experience shows that the increased cost of tutorial time is more than compensated for by the staff time saved thanks to improved student motivation and by the delivery of lectures and routine testing via interactive software. This offers an opportunity for developing a new, truly 'contemporary' role for tutor-learner interactions, and more relevant pathways of influence bypassing the box ticking boards - at least in the first instance - as well as impacting inconspicuously on organisational changes in University. Furthermore, it acts as a powerful agent in assuring perpetual re-positioning and re-negotiation of the ever changing 'human content' of inquiry.

\section{The Gaps to Bridge}

Although for some time now front line research has depended for its success on effective synergy among the team who bring in a great variety of expert knowledge and contacts, the university politics stands on at least paper autonomy of its subject based departments. This amounts to academic feudalism, with jealously guarded territories and their boundaries. For what is at stake are jobs and promotions. Apart from notable exceptions, the methodologies and the structure of curriculum delivery are further handicapped by the box ticking managerialism anxious to live up to the persisting glow from the golden age of identity politics designed to close off any channels or even 'words' that might be 'challenging'. Apart from notable exceptions, anybody mentioning open ended-ness, be it in knowledge acquisition or management - not to speak of multi-disciplinarity, is a charlatan, 'anything goes' post-modernist, or just a persona non grata.

The computerisation of curriculum delivery and performance evaluation, particularly when structured and managed by bodies partly or entirely external to university, at least in principle presents a deadly threat to the most treasured values and customs of academia, to the personal power, influence and status of the professoriate, to the control over the syllabus content, and a monopoly in personal access to students. For the syllabus is almost always dominated by the ethos - if not the letter - of the 
101 problems (solutions) constituting this or that specialist degree. The solutions delivered and examined there are 'clear and distinct' because they are a product of years of selections, simplifications, and brilliant conceptual manipulations of physical and social reality. The methodologies and the vocabulary that inform the delivery of such pre-packaged solutions are, again apart from a few notable exceptions, hostile to, indeed incompatible with any 'open decision spaces' which can only be dealt with by compromises required for matching the real world demands of different levels of competing complexity. For these demands lead to lines of inquiry crossing the discipline boundaries and encountering interplay of human and machinic contributions and structures.

This professorial hostility is far from being just a frivolous caprice. For it draws on the deepest and most cherished instincts of academics. For many, University as we know it still is one of the last surviving institutions - be it only just - capable of defending the Common, the public space without which human rights, free will, freedom of speech etc. lose any meaning. With almost all structures of University having been more or less lost to the merchants of 'neo-liberal post-modernity', the autonomy of the academic subject which in practice rests in its Departmental territory appears to be the last bastion to defend. Rightly or wrongly, in the present climate any attempt to open its walls without very credible safeguards - no matter how worthy the motive - is bound to be seen as a threat to replace the human centred character of University with an externally imposed machinic structure controlled chiefly by ephemeral interests of money making.

\section{And Now How it Happens: Of Stones, Animals, Human Beings... and Angels?}

The quest for effective delivery and measurement of competence to make decisions in conditions dictated by the networked, multi-dimensional reality of today raises a broad range of conceptual and leadership questions. Some of these are being addressed in a variety of ways [22]. What is of interest here is the methodological gap between the competence the productive structures of society need and the way of thinking that informs the mainstream curriculum delivery. It is, significantly, also the gap separating the undergraduate and state of the art research and production practices. For the latter require, in addition to a specialist background, the skills in problem formulation and synergy reaching well outside departmental boundaries - and without attempting to become a walking encyclopaedia!

The problem of bridging this gap is certainly not new. Since about hundred years ago, thinkers in all domains of human endeavour have been looking for a way of living up to the new relations between humans and products of their work bearing the signature of rapidly changing divisions of labor. In the course of this effort, a creative space was born for developing a generic methodological shift, away from the anthropomorphic Hegelian History and towards a more polyphonic, 'genealogical' thinking free to cross the boundaries of what had been until then regarded as autonomous spheres of human endeavour, e.g. art and science. The flavour of this process is perhaps captured metaphorically in the title of this section, borrowed from Walter Benjamin's work, and more so in his pioneering
Arcades Project [23] (for comments amplifying the meaning of this title, and explaining the key methodological themes of Benjamin's intervention (see Buck-Morss' monograph [24] or a more recent one of Hanssen [25]) which has been an inspiration for this (e.g. [26]) and many other research programs.

Once it became established, in the first decades of the $20^{\text {th }}$ century, that there is no eternal, 'static' universe and a priori truths, the concept of Universal History as a necessary movement of the self-understanding of the collective mind or Spirit became just another brilliant archival document. It left a methodological void. For that to be filled, a radical departure was found by thinkers like Benjamin in a U-turn, in replacing the top down, speculative, doctrinaire approach with a proto-empirical genealogy. This is the way an archaeologist works when uncovering a site suspected to contain a buried city, by taking a layer after layer of materials and laying them down for recoding, as if without any preconceived idea as to what they 'mean'. It is only later that a discourse is initiated and lines are drawn through the layers to make connections between related bits of pottery or bones, and links to larger views are made. While the data is there to ensure that it is not 'anything goes', the process is always already open to iterative re-formulation of the problem, and to optimum contextualisation of the final outcome and its limits of applicability.

Benjamin's Arcades Project, and particularly some of its chapters or Konvolutes, is really a master class - be it only half-finished - of how to develop an alternative notion of history via an archaeological-genealogical method. It is a sequence of exploratory moves, a journey which constitutes the place in terms of the process of journeying through it. It is grounded in perpetual openness to re-definition and renegotiation of the (local) terms in question and their limits. To create and maintain this openness - even in the face of a catastrophe - seems to be the necessary condition for sustaining a functional notion of sustainability, and definitely the core of any functional meaning of 'sustainable development'. For that which is to be sustained is always a function of time and place [27], while the need for sustaining the openness guaranteeing the possibility of sustainable development is a fundamental constant! And since here its focus has been moved away from Kant's (phenomenologist's, social constructivist's, conceptual artist's, and many others) abstractions to the human, bodily site of experimentation, it is one that, significantly, offers a prospect for developing a new, up to date concord between humans and the elaborate machinic and 'virtual' structures they had been creating and that threaten to dominate them.

For the genealogical process such as that advocated here to begin to make any difference, it is essential - before embarking on any culture wars with masters of the Academia - to clear the mines left in the playing field by the conquerors. It is, first of all, to begin to understand and know how to undermine and render harmless the hidden and visible barriers cast into the daily praxis of higher education in terms of what is often termed as 'Cartesian opposites'. For the most fundamental of these obstacles is the hierarchical structure that such 'absolute' divisions impose, such as those between the human and non-human, soul and body, yes and no, right and wrong, male and female, art and science, being and non-being, etc. It is not to ignore such differences but not to confuse them with legitimation of territorial 'hierarchies'. 
The principle of 'disinterested enquiry' - by the human mind, separated, at least for the purposes of that inquiry, from its body and from the world of autonomous objects to be investigated, measured and quantified - has led to brilliant discoveries of 'soluble problems' in physical and social sciences resulting in an unprecedented growth of knowledge and its application, 'technology'. The key moment of this process has been the separation of pure and practical reason, of knowledge generation from knowledge transmission and application. The price was the removal of any serious limits from what was produced by this Newtonian reason. Only a madman opposes the Rational Truth in action! In Kant's day, it was surely a liberating move. Certainly, Nature could still be to a good approximation regarded as a neutral referent, something out there, since science remained cloistered off in monkish quarters. Indeed, for Newton physics was still a celebration of the glory of God's creation. Of course, by now the conquest of Nature by human interventions is much advanced and has much invaded the social and bodily structures everywhere, often blurring the Cartesian opposites into heterogeneous, hybrid structures. Consequently, it is much more realistic to view what we encounter not only as a thing out there, as a collections of atoms and molecules bonded together by forces governed by 'natural laws', but also in terms of how we encounter and use them, how we 'register' their existence, that is in terms of the dynamics of the process in which 'existence' is seen, recorded and reacted upon. This choice of parameters and meaning making tools in recognition of local, temporal, and site related properties replaces the abstract notion of object autonomy with the 'operational' meaning of its 'existence' and 'knowledge'. This makes it possible to model and act upon functional links leading across the subject boundaries, clearly acknowledging the approximate and temporal character of the model before us, without having to worry about 'higher' constrains. Its grounding in the concrete material records protects it from excessive radicalism prepared to throw away genealogy and replace it with overzealously 'creative' 'reading without bounds' (e.g. apparent already from the title of otherwise brilliant paper by Eshun [28]). The thing or event 'is', in a dynamic sense, as it is 'discovered' or registered by a particular 'experiment' and in the specificity of that encounter. This 'registration' is a record which couples the thing to its immediate surroundings, the part of the problem necessarily excluded from the dis-interested 'universal truth' about existence expressed in a scientific account of, say, a molecular composition of matter.

This concept of existence as 'dynamic ontology' concentrating on 'local' input-output parameters is particularly useful for dealing with interfaces between humans and machines, and with interactive networks and invasive tools in particular. It is because in that case for conceptualisation (meaning and decision making) to take place, the thinking mind must be capable of recognising, without any doctrinaire imposition, the contingent, approximate and dynamic character of the blocks which serve as a basis for communicational processes and for 'recording' the event. To put it more precisely, instead of 'fixed' objects, it is then more profitable to follow the intelligent machine designer - philosopher Brian Smith and view objectness (thingness) as a dynamic capacity to be affected and affecting, "to behave ...or be treated as an object" [29]. This notion re-establishes the pre-Cartesian primary role of the body and shifts the task of providing directionality from transcendental systems (of physical, social or aesthetic "laws") to the sites of making and connecting, the locations of rising and decaying energy. It is this directionality that the Kantian Critiques and ascending Universalism took away and transferred into 'Transcendental Necessity'.

In spite of the large number of 'long words' and abstractions borrowed from philosophy and sociology employed in this methodological tour de force, students have always been quick to grasp the essence of how to go about implementing it - once they were helped to choose a project topic (place) that would genuinely interest them. It helped being taken through the motions in some detail as described in earlier studies (e.g. [1] and refs. therein)! However, the difficulty often arises when it comes to pinning down the point at which the break with the traditional views, as caused by the social conditions and attitudes created in response to new technologies, manifests itself in a concrete shift to different set of parameters of performance, scales, and forms of measurement (assessment), and so on. The case studies in books cited here, e.g. those by Crary and Kwinter, Inns, Fuller, Lovink, Morris [30], and Pearson may also serve as a valuable source for preparing projects for promoting this pedagogy. These examples cover a wide range of accessible themes from science and technology to arts and humanities.

\section{Opening the Space for a New Social Contract about Knowing and Being}

It is argued above that the core of 'competence' is increasingly located in the action space where success depends on effective recognition of relevant pathways through a beehive of knowledge and power structures laid down by the digital age. This is also the space in which the contributions of the learner and tutor, the University with its human intellectual capital and professional channels are brought together. Here their relative merits and values are projected upon the human content of the contributions offered by all actors. It is also a useful means for making concrete and material records of the path along which the candidate proceeded to the end of the task, a concrete pictorial and factual record and therefore something a nonexpert interviewer can also appreciate as a demonstration of what the candidate was awarded the degree for. The "iterative procedure" is also a way of building up of a 'genealogical' account, a local knowledge map [1] of what is being done, by whom and in what order, recording not just successes but also the compromises and diversions, personal and institutional contributions at each iteration. It is then also a documentary 'diary' of personal development in the course of recognising, formulating and implementing the task in hand. It is an open book not only to show how a bridge was finally designed and built, but also what social and technical concerns, obstacles and achievements this process has led to, who benefited from it and why, how it was possible to fit it into the broad range of infrastructures in that place. It is this "archaeological-genealogical aspect" of the method that is the ground for making visible and available for debate the human content of the task viewed at the site of experimentation and production.

It is a challenge to the leadership in higher education gradually to restructure the curriculum delivery so that the 
shift towards this scenario can take place, and the terms of reference for teaching, learning, and examination changed as they had changed in most research and production structures. Indeed, the problem formulation and modeling in the complex space spanned by disparate knowledge and power systems has been much developed by researchers having to match in various contexts the human and machinic structures (e.g. Sornette's book [3] contains a number of accessible - and well supported by explanations of key modeling principles - examples from topical problem domains). Instead of seeking pre-packaged 'solutions' and 'predictions' from 'long-range' grand models born out of the $19^{\text {th }}$ century optimism (ref. [30] contains a particularly instructive case demonstration of the methodological shift from grand system building to contemporary parameterization based on quantitative data), theirs is a systematic application of an empirically based response model, a process of iterations and re-enacting until the most likely picture comes out. For instance, to understand better a town's infrastructure for food supply, it may be insightful to test its response to a crop failure in a distant region [31]. If one wants to appreciate the foot and mouth epidemic, one must get as much empirical data as possible and set up in an iterative procedure of reenacting what might have happened and why. The preparations of Barack Obama for the final debate in his first presidential bid consisted not only of the usual briefings and coaching but also of a full scale "preenacting' of the debate, not on a computer screen but in the real place and with real people, etc.! Indeed, the methods for dealing with complex physical and social systems for which there are no clean 'solutions' have been widely used in the last decade or so, from historians and weather forecasters to car makers and stock market analysts. The IBM programs for "Deep Blue" that defeated the world chess champion Gary Kasparov worked in a very similar manner!

Textbooks about 'competence with responsibility' are long overdue. Whatever else they may become, they will be grounded in 'response models'. They will describe how best to initiate a set of parameters to start effectively the iteration which will ultimately determine the desired outcome in place of some pre-mediated fixed target. It will be as a procedure, as a tool for the dynamics of moving forward and a guarantee of certain limits on conducting it, not as a set of values and doctrines. What the realistic form of the task is, as well as what the final shape, aims, and value of the product - or a mark for a student work is, can only be known when the iteration converges, i.e. when the outcome of the next round is so close to that of the last that the difference lays within the margin of acceptable compromise.

\section{Conclusions}

Manuals for human-oriented competence development in the $21^{\text {st }}$ century have yet to be written. But whatever else they may become, the successful ones will not be in the form of another declaration of rights, of another document of definitions no matter how elaborate and detailed. At best they will be testable practices in the form of 'response models'. They will assure, much more realistically then any top-down doctrine based on speculative assumptions not amenable to proper empirical testing, the conditions for perpetual re-negotiations of the parameters needed to model the sub-space of interest and of the limits on conducting such procedures.

As for the 'end of history', the 'linear' history of liberation of humans from ignorance and superstition inaugurated by the Enlightenment thinkers like Kant and Hegel - right up to the (in)famous intervention of Fukuyama [32] - has ended only in the sense that human 'goings and doings' have been gradually branched into many different levels and 'spaces' of being, each rising and decaying as their energy supply comes and goes. The one set of 'measurements' - that of the Newton metric adopted by Kant - has ultimately led human endeavour well beyond its bounds and into novel 'forms of existence', each with a different level of complexity, scales, and units of performance. It is vital not only for tomorrow's profitability but also for the future wellbeing of humans at large that the decisions made by competent minds are guided by recognition of this new operational regime and its significance whether in law making or in designing an airport. Its course - the process of liberation of humans from enslavement by other human beings and by caprices of Nature, is as much alive as ever though it is cast into a chaotic, complex, multi-dimensional action space of today. The form and direction of any 'line' of 'history' or genealogy extracted from such a beehive is always a function of space and time peculiar to the 'level' of existence, of the place in which the encounter is being unravelled [30].

\section{References}

[1] Jaros, M., "Leadership and Methodology Challenges in Higher Education: Developing Competence in the Digital Age", Global Education Review 2, 64-89, 2014.

[2] Luhmann, N., Social Systems, transl. Bednarz, J. Jr. and Baecker, D., Stanford University Press, Stanford, 1995.

[3] Sornette, D. (2003). Why Stock Markets Crash. Princeton University Press, Princeton, 2003.

[4] Thaler, R.H., Sunstein, C.R., Nudge. Yale University Press, Yale, 2008.

[5] Instructive and accessible examples, from low to high levels of sophistication, can be found in Kelly, K., Out of Control, Fourth Estate, London, 1994, Lovink, G., Ed. Uncanny Networks. Cambridge: MIT Press, Cambridge, 2004, Crary, J., Kwinter, S., Eds., Incorporations, MIT Zone, New York, 1992, Pearson, K.A., Viroid Life, Routledge, London, 1997, Raunig, G. A Thousand Machines, Semiotext(e) (Intervention Series 5), Los Angeles, 2010.

[6] Lyotard, J-F., The Postmodern Condition, trans. G.Bennington, G., Massumi, B., Manchester University Press, Manchester, 1986.

[7] Standish, P., "Heidegger and the Technology of Further Education", $J$. Philos. of Education of Great Britain 31, 439-460, 1997.

[8] Zizek, S., First as Tragedy, Then as Farce, Verso, London, 2009

[9] Mirowski, P., Never Let a Serious Crisis Go To Waste, Verso, London, 2013.

[10] Blömeke, S., Zlatkin-Troitchanskaia, O., \& Fege, J., Eds., Modeling and Measuring Competences in Higher Education, Sensepublishers, Rotterdam, 2013.

[11] Shavelson, R.J., "An Approach to Testing \& Modelling Competence", in Blömeke at. al., Eds., Modeling and Measuring Competences in Higher Education, Sensepublishers, Rotterdam, 2013, 29-44.

[12] Inns, T., Ed.,Designing for the $21^{\text {st }}$ century, Glover, London, 2010.

[13] Castells, M., The Rise of the Networked Society, Blackwell, London, 2000.

[14] Harvey, D., The Enigma of Capital, Profile Books, London, 2010.

[15] Westra, R., The Evil Axis of Finance, Clarity Press Inc., Atlanta, 2010 . 
[16] ref. 10, p.1.

[17] Wilson, A., Knowledge Power: Interdisciplinary Education for a Complex World, Routledge, London, 2010, 114.

[18] Grafton, A.T., "Can the College be Saved?", The New York Review of Books LIX, 22-24, May 22, 2012.

[19] Ryan, A., "One Virtue at a Time, Please", The New York Review of Books LIX, 54-55, June 21, 2012.

[20] Bromwich, D., "The High-Tech Mess of Higher Education", The New York Review of Books, LXI, 50-52, August 14, 2014.

[21] Palmer, J.A. (Ed.), Fifty Modern Thinkers in Education, Routledge, Oxford, 2001.

[22] Blömeke, S., Zlatkin-Troitschanskaia, O., Eds., Modeling and Measuring Competences in Higher Education: 23 research projects on engineering, economics and social sciences, education and generic skills of higher education students, KoKoHs Papers 3 , www.kompetenzen-im-hochschulsektor.de, November 2013.

[23] Benjamin, W., The Arcades Project, transl. Eiland, H., McLoughlin, K., Harvard, Cambridge, Mass., 1999.

[24] Buck-Morss, S., The Dialectics of Seeing, MIT Press, Cambridge, Mass., 1989.
[25] Hanssen, B., Walter Benjamin's Other History, University of California Press, London, 2000.

[26] Jaros, M., Deakin-Crick, R., "Personalised Learning for the PostMechanical Age", Journal of Curriculum Studies 39, 423-440, 2007.

[27] Jaros, M., "Towards Re-definition of Space-ness in the Postmechanical Age: Methodological Notes", Landscape and Urban Planning, 83, 84-89, 2007.

[28] Eshun, K., "Everything Was To Be Done. All Adventures Are Still There.” In Lovink, G., Ed., Uncanny Networks, MIT Press, Cambridge, Mass., 2004, 348-359.

[29] Smith, B.C., On the Origin of Objects, MIT Press, Cambridge, 1996, 36.

[30] Morris, I., Why the West Rules - For Now, Farrah, Strauss and Giroux, New York, 2010.

[31] Fuller, S., "Social Epistemology and the Research Agenda of Science Studies", in Science as Practice and Culture, Pickering, A., Ed., Chicago University Press, Chicago, 1992, 390-428.

[32] Fukuyama, F., The End of History and The Last Man, Avon Books, New York, 1992. 